\title{
Treatment of Primary Liver Tumors and Liver Metastases, Part 1: Nuclear Medicine Techniques
}

\author{
Nicholas Voutsinas, Safet Lekperic, Sharon Barazani, Joseph J. Titano, Sherif I. Heiba, and Edward Kim \\ Department of Radiology, Icahn School of Medicine at Mount Sinai Hospital, New York, New York
}

Learning Objectives: On successful completion of this activity, participants should be able to describe (1) the different indications for 90Y radioembolization, (2) the technical aspects of performing the therapy and pre-planning angiography, and (3) the follow-up imaging findings and potential complications.

Financial Disclosure: Dr. Kim discloses serving as a consultant for BTG and Philips Healthcare and serving on the advisory board for BTG and Boston Scientific. The authors of this article have indicated no other relevant relationships that could be perceived as a real or apparent conflict of interest.

CME Credit: SNMMI is accredited by the Accreditation Council for Continuing Medical Education (ACCME) to sponsor continuing education for physicians. SNMMI designates each JNM continuing education article for a maximum of 2.0 AMA PRA Category 1 Credits. Physicians should claim only credit commensurate with the extent of their participation in the activity. For CE credit, SAM, and other credit types, participants can access this activity through the SNMMI website (http://www.snmmilearningcenter.org) through November 2021.

${ }^{90} \mathrm{Y}$ radioembolization is an increasingly used treatment for both primary and metastatic malignancy in the liver. Understanding the biophysical properties, dosing concerns, and imaging appearance of this treatment is important for interventional radiologists and nuclear medicine physicians to provide important therapy. ${ }^{90} \mathrm{Y}$ radioembolization is efficacious and safe, although the possibility of complications does exist. This article provides a comprehensive in-depth discussion about the indications for ${ }^{90} \mathrm{Y}$ radioembolization, reviews the role of preprocedural angiography and ${ }^{99 \mathrm{~m} T c-m a c r o a g-}$ gregated albumin scans, illustrates different dosing techniques, compares and contrasts resin and glass microspheres, and describes potential complications.

Key Words: ${ }^{90}$ Y radioembolization; hepatocellular carcinoma; liver, cancer; MAA

J Nucl Med 2018; 59:1649-1654

DOI: 10.2967/jnumed.116.186346

$\mathbf{T}$ he use of radiation to treat malignancy is not a recent invention; however, efforts have been made to improve the precision of this therapy. Intraarterial injection of the radioactive isotope ${ }^{90} \mathrm{Y}$ has been discussed in the literature since 1965 , with varying rates of success (1). In 1965, attempts were made to use this isotope to treat primary liver and pancreatic cancers, with positive results and limited complications. ${ }^{90} \mathrm{Y}$ is a $\beta$-radiation emitter with a mean decay energy of $0.94 \mathrm{MeV}$, which if delivered to the tumor site will cause cellular breakdown and tumor necrosis $(2,3)$. The isotope's half-life is approximately $64 \mathrm{~h}$, with tissue penetration of approximately $1 \mathrm{~cm}$, limiting exposure to the surrounding parenchyma $(2,3)$. Intraarterial injection of radiation particles has some advantages over systemic radiation. It limits

Received Mar. 9, 2018; revision accepted Jul. 18, 2018.

For correspondence or reprints contact: Nicholas Voutsinas, Icahn School of Medicine at Mount Sinai Hospital, 1 Gustave Levy Place, Box 1234, New York, NY 10029.

E-mail: nicholas.voutsinas@mountsinai.org

Published online Aug. 2, 2018.

COPYRIGHT (c) 2018 by the Society of Nuclear Medicine and Molecular Imaging. the exposure of normal liver parenchyma to radiation, and it places the highest possible dose of radiation adjacent to the tumor when appropriately targeted (2). Additionally, the limited tissue penetration makes intraarterial injection safer for medical personnel and the patient's family (4). As medical technology has advanced, administration of ${ }^{90} \mathrm{Y}$ has improved and become more widespread, making it an effective tool in the fight against malignancy.

\section{INDICATIONS}

Since the initial description of intraarterial ${ }^{90} \mathrm{Y}$ therapy, its use in the treatment of primary liver tumors has been studied $(1,5,6)$. Hepatocellular carcinoma was historically difficult to treat because systemic chemotherapy had poor response rates and because external-beam radiation caused side effects and significant damage to radiosensitive liver parenchyma $(5,7)$. Traditionally, if hepatocellular carcinoma is localized, it is considered surgically resectable; however, some patients are poor surgical candidates and others already have multifocal or bilobar disease at presentation, limiting treatment options $(4,8)$. Initial studies demonstrated that intraarterial ${ }^{90} \mathrm{Y}$ microspheres could cause significant tumor necrosis because the tumor is radiosensitive (5), and that unresectable hepatocellular carcinoma showed improvements in tumor vascularity and lifespan (9). Later studies showed that, in localized disease, outcomes for ${ }^{90} \mathrm{Y}$ radioembolization were similar to or better than those for other locoregional therapies, such as transarterial chemoembolization or ablation $(10,11)$.

Intrahepatic cholangiocarcinoma is the second most common primary liver malignancy (12). When the disease is unresectable, prognosis is poor, although combination chemotherapy (gemcitabine and cisplatin) has been shown to improve overall survival, but often with systemic toxicity. Intrahepatic cholangiocarcinoma is also radiosensitive, and palliative treatment with ${ }^{90} \mathrm{Y}$ radioembolization has shown improved median survival with limited side effects (12-13).

Colorectal cancer is one of the most common malignancies worldwide, and the primary site for metastasis is the liver because of portal venous drainage $(14,15)$. Standard therapy for metastatic colorectal cancer is currently a chemotherapy regimen consisting of fluorouracil, leucovorin, and oxaliplatin (FOLFOX); however, combination with ${ }^{90} \mathrm{Y}$ therapy may be beneficial, especially in patients who are refractory to chemotherapy $(14,16-18)$. Multiple 
clinical trials have been performed to test whether there is a benefit to combination therapy, with mixed results $(16,19)$.

Neuroendocrine tumors are a broad classification of malignancy that commonly originates from the digestive tract (20). Similar to colorectal cancer, neuroendocrine tumors commonly metastasize to the liver because of portal venous drainage. Intraarterial embolization of liver metastases without radiation was successful as palliative therapy in patients with disease too extensive for surgical resection, and this technique was amplified by the introduction of ${ }^{90} \mathrm{Y}$ microspheres, as the tumors are radiosensitive $(17,20)$. For treatment of neuroendocrine tumors, the Food and Drug Administration recently approved the radiopharmaceutical Lutathera ( ${ }^{177}$ Lu-DOTATATE; Advanced Accelerator Applications), which may supplant ${ }^{90} \mathrm{Y}$ radioembolization for this use (21).

In addition to salvage therapy and primary treatment of various malignancies for patients who have contraindications to surgery, ${ }^{90} \mathrm{Y}$ microspheres can be used as an adjunct to surgery (22). ${ }^{90} \mathrm{Y}$ microsphere therapy is efficacious in downstaging patients with hepatocellular carcinoma, metastatic colorectal cancer, and cholangiocarcinoma, making them more amenable to surgical resection $(13,22)$. Radioembolization can also reduce tumor burden, slow disease progression, and provide a bridge to liver transplantation (22).

\section{PRETREATMENT ASSESSMENT}

Although preprocedural imaging will reveal the target lesion's location, the number and location of specific hepatic artery branches supplying the tumor are not easily identified (23). Preprocedural hepatic arterial mapping is standard before ${ }^{90} \mathrm{Y}$ radioembolization to ensure proper delivery of the dose, thus maximizing efficacy and reducing potential nontarget embolization. Direct hepatic angiography (Fig. 1) consists of filling the hepatic artery and its branches with contrast material under fluoroscopic guidance, allowing the performing physician to visualize the tumor, the vessels supplying the tumor, and any branches that may supply other organs. Specifically, the gastroduodenal and right gastric arteries may arise from hepatic branches distal to the origin of the tumor-supplying artery. During this preprocedural mapping, arteries supplying other organs can be embolized to prevent ${ }^{90} \mathrm{Y}$ from being misdirected to areas other than the liver parenchyma, embolizing these nontarget areas and causing severe side effects (24). Hepatic artery mapping before ${ }^{90} \mathrm{Y}$ can also be enhanced with cone-beam CT and guidance software to enhance identification of tumors and their vascular supply (Fig. 1) (25).

In all patients, there is some degree of blood shunting between the liver and lungs, called a lung shunt fraction, which may result from normal collateral vessels, hypervascular tumor vessels, or arteriovenous malformations $(26,27)$. The lung shunt fraction is calculated after the injection of radiolabeled ${ }^{99 \mathrm{~m}} \mathrm{Tc}$-macroaggregated albumin ( ${ }^{99 \mathrm{~m} T c-M A A)}$ during preprocedural mapping (28). ${ }^{99 m}$ Tc-MAA particles have a size and distribution similar to that of ${ }^{90} \mathrm{Y}$ microspheres, allowing for an estimation of potential radiation exposure to the lungs from ${ }^{90} \mathrm{Y}$ (29). Multiple small doses of 99mTc-MAA totaling approximately $0.148-0.185 \mathrm{GBq}$ are injected via a hepatic arterial catheter and distribute throughout the liver $(23,28,29)$. Postprocedural imaging is obtained with planar images and SPECT of the abdomen, along with low-dose CT for anatomic localization of radiotracer activity (Fig. 2) (28). To determine the lung shunt fraction, the computer calculates the total count contributed by increased radiotracer uptake within the lung and divides that

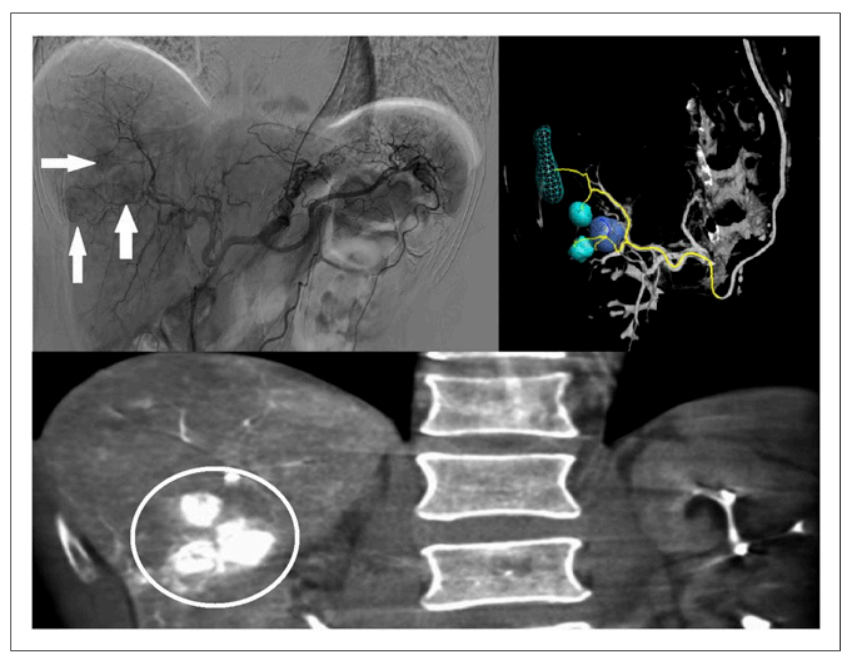

FIGURE 1. Images acquired during hepatic angiography of 64-y-old man scheduled for ${ }^{90} \mathrm{Y}$ radiation lobectomy. (Top left) Catheter in celiac axis after left radial access, with multiple foci of contrast medium (arrows) in liver consistent with tumors. (Bottom) Coronal cone beam CT of liver, with multiple tumors (circle) seen in right hepatic lobe. (Top right) Three-dimensional reconstruction with targeting software, demonstrating tumors and arterial supply.

by the sum of counts within the lung and liver (Fig. 3). If the lung shunt fraction would result in more than 25 Gy (for resin microspheres) or $30 \mathrm{~Gy}$ (for glass microspheres) in a single administered dose or greater than a 50-Gy cumulative dose depositing in the lungs, the risk of injury to the lungs is a contraindication (Fig. 4) (30).

Post-99mTc-MAA SPECT/CT can be used to determine radiotracer uptake in the abdomen as well, including within the liver and extrahepatic organs (31). If the ${ }^{99 \mathrm{~m}} \mathrm{Tc}-\mathrm{MAA}$ is administered correctly, increased activity should be noted within the portion of the liver being treated. Deposition of ${ }^{99 m}$ Tc-MAA in nontarget liver parenchyma may be due to accessory or parasitized arteries; preplanning angiogram images should be reviewed for potential collateral vessels. Radiotracer activity in other abdominal organs

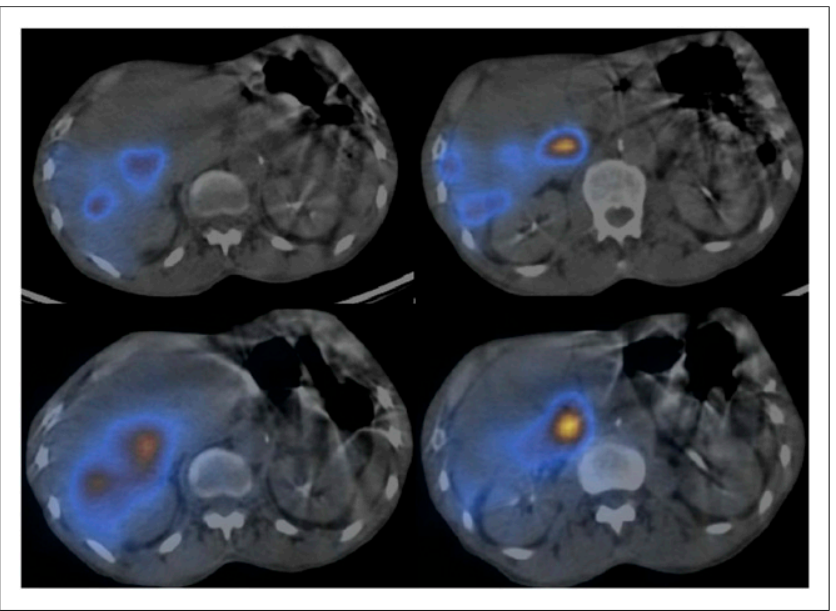

FIGURE 2. (Top) SPECT/CT images after injection of $99 \mathrm{mTC}-\mathrm{MAA}$ in right hepatic artery of 64 -y-old man. (Bottom) SPECT/CT images of same patient after ${ }^{90} \mathrm{Y}$ microsphere radiation therapy. Radiotracer deposition is concordant between the 2 studies. 


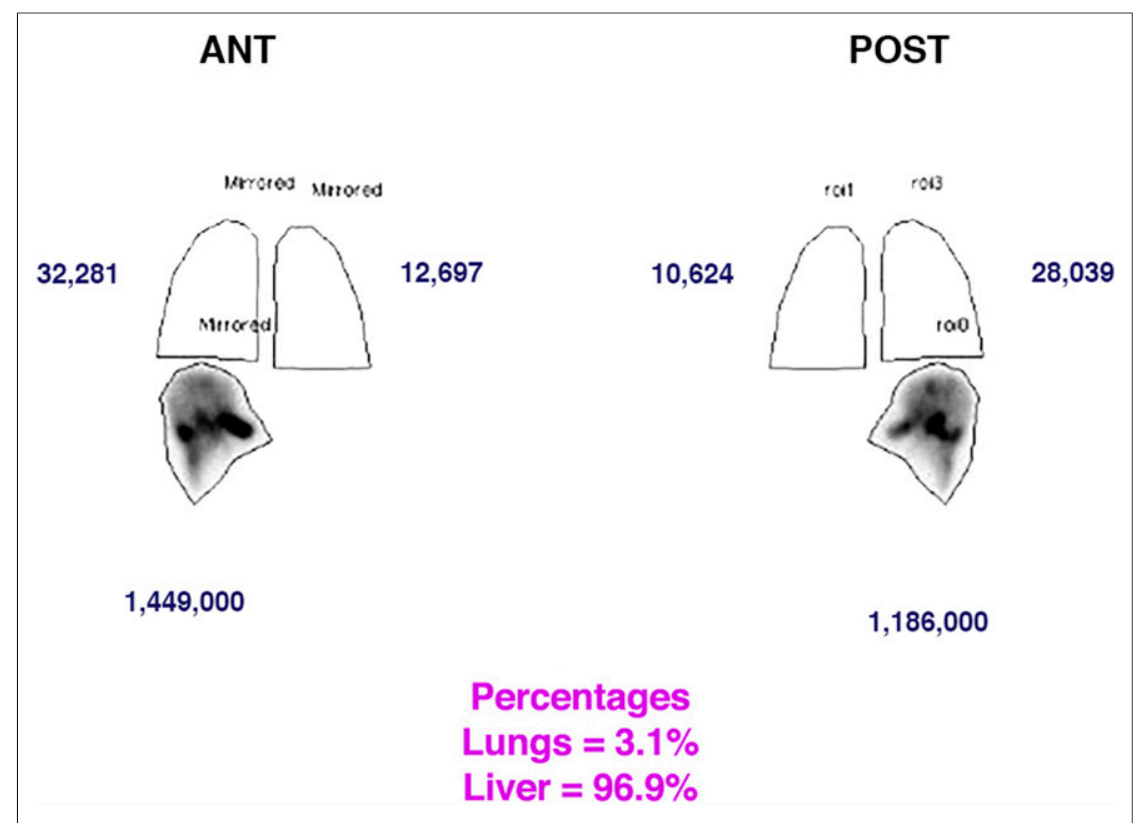

FIGURE 3. Anterior and posterior planar whole-body scintigraphy after ${ }^{99 m}$ Tc-MAA intrahepatic arterial injection. Counts in regions of interest around lung and liver reflect radiotracer deposition. From these counts, computer calculates percentage in liver and percentage in lung (lung shunt fraction). This $64-y$-old man had lung shunt fraction of $3.1 \%$, which was acceptable for ${ }^{90} Y$ microsphere radiation therapy.

(Fig. 5) may result from other abdominal vessels arising from a position distal to the site of the ${ }^{99 m}$ Tc-MAA injection. These findings would put the patient at significant risk of nontarget embolization if these arteries are not prophylactically embolized during the mapping procedure. Occasionally, prophylactic embolization can also cause new collateral pathways to the enteric structures-pathways large enough to divert ${ }^{90} \mathrm{Y}$ microspheres from their intended targets (32).

\section{DOSING CONSIDERATIONS}

The typical range of planned absorbed doses to target liver tissue in ${ }^{90} \mathrm{Y}$ microsphere therapy is about $80-120$ Gy (33). The dose absorbed by the liver can be measured as the amount of energy or radiation activity provided per mass of treated liver multiplied by a dose constant, after factoring the loss due to lung shunting. The liver mass to be treated is calculated by measuring the volume on $\mathrm{CT}$ and converting that volume to a mass using a conversion factor of $1.05 \mathrm{~kg} / \mathrm{L}$ for resin microspheres or $1.03 \mathrm{~kg} / \mathrm{L}$ for glass microspheres. Dose calculations for ${ }^{90} \mathrm{Y}$ radioembolization are performed under assumptions of uniform dose distribution, complete ${ }^{90} \mathrm{Y}$ decay, and accurate liver mass measurement. Given these assumptions, empiric dosimetry models have been developed to estimate the administered activity required to reach a desired liver target dose without surpassing a maximum lung dose.

There are 2 different types of ${ }^{90} \mathrm{Y}$ microspheres currently available: glass and resin (30). Glass microspheres, also known as TheraSphere (BTG), are 20-30 $\mu \mathrm{m}$ in size and can be formulated into doses between 3 and $20 \mathrm{GBq}$. Resin microspheres, also known as SIR-Spheres (Sirtex), are 20-60 $\mu \mathrm{m}$ in size and have a maximum dose of $3 \mathrm{GBq}$ (34). Currently, glass microspheres are Food and Drug Administration-approved under a humanitarian device exemption for radiation treatment in patients with hepatocellular carcinoma $(33,34)$, Conversely, resin microspheres are Food and Drug Administration-approved for unresectable metastatic colorectal cancer to the liver $(33,34)$.

Dosing calculations can be performed for either radiation lobectomy or segmentectomy. Although there is no universal dosing pattern for radiation lobectomy, studies have reported a median dose of 112 Gy delivered to the treatment site for radiation lobectomy (35). Like radiation lobectomy, radiation segmentectomy has dosing calculations intended for treatment of the entire segment in which the lesion is located; however, in radiation segmentectomy the intraarterial therapy is injected from a vessel supplying 1 or 2 segments, instead of from the lobar artery as in radiation lobectomy (36).

The exact dosing calculations depend on which type of microsphere is used for radioembolization $(35,36)$. Approximately 40-80 million resin microspheres result in a maximum activity of $3 \mathrm{GBq}$, whereas glass microspheres demonstrate similar radioactivity with only $1-8$ million particles, resulting in greater activity per sphere and a potential maximum activity of $20 \mathrm{GBq}$. With resin therapy, doses are based on activity, not target radiation dose. The empiric dosimetry models determine activity based on maximum activity and body surface area (BSA), with modifications for tumor fraction in liver and lung shunting. For resin microspheres, the target radiation dose is limited to less than 80 Gy for liver, but with glass microspheres, doses are typically $80-120$ Gy. The BSA method is the primary way to calculate the ${ }^{90} \mathrm{Y}$ dose for resin microspheres (33).

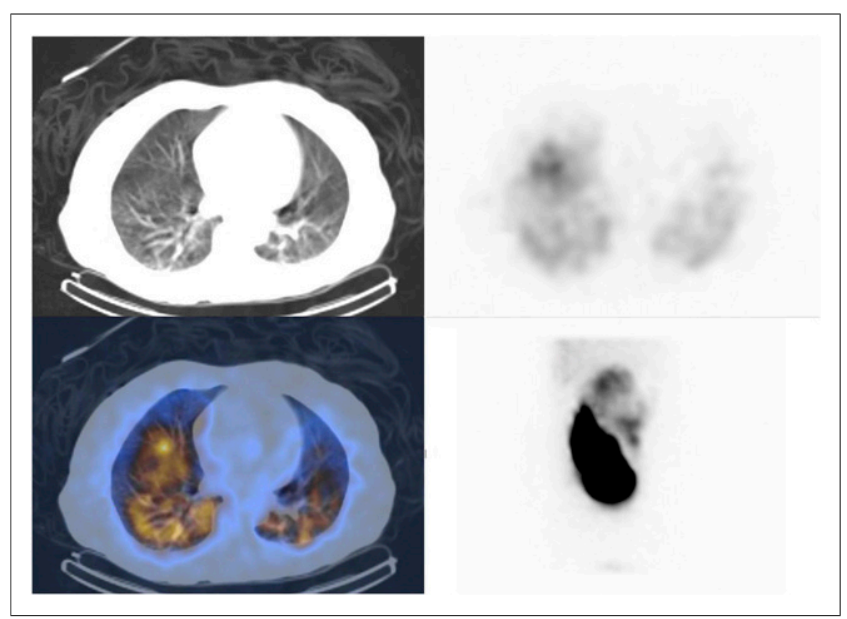

FIGURE 4. CT of lungs (top left), SPECT/CT of lungs (bottom left), axial scintigraphy of lungs (top right), and planar scintigraphy of lower chest and abdomen (bottom right) in 54-y-old man with hepatocellular carcinoma after his ${ }^{99 m}$ Tc-MAA examination demonstrated bilateral uptake within lungs after administration to liver. This patient's lung shunt fraction was calculated to be $58 \%$ (acceptable fraction is $<20 \%$ ). 


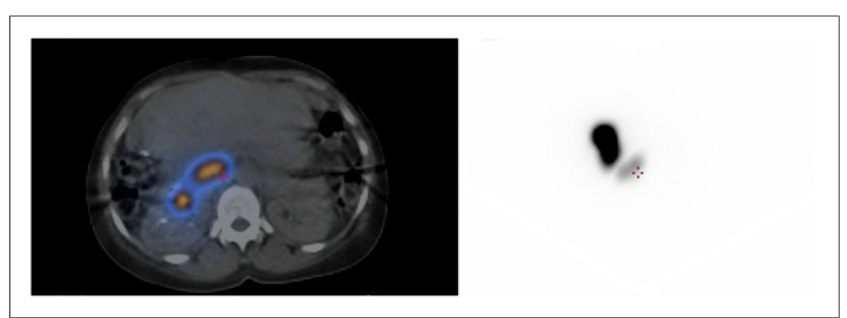

FIGURE 5. SPECT/CT (left) and planar scintigraphy (right) demonstrating ${ }^{99 m}$ Tc-MAA radiotracer deposition in small bowel, secondary to shunting from liver arteries. This $57-y$-old man is no longer a candidate for ${ }^{90} \mathrm{Y}$ radioembolization because of risk of nontarget embolization and duodenal ulceration.

Empiric models for ${ }^{90} \mathrm{Y}$ radioembolization base the administered dose to the entire liver on the percentage of liver volume occupied by the tumor (37). On the basis of this nominal modeling, if the tumor volume is less than $25 \%$ of the total liver volume, $2 \mathrm{GBq}$ should be administered. If the tumor volume is $25 \%-50 \%$ of the total liver volume, $2.5 \mathrm{GBq}$ should be administered. Finally, if the tumor volume is greater than $50 \%$ of the total liver volume, $3 \mathrm{GBq}$ should be administered The BSA method for dosing ${ }^{90} \mathrm{Y}$ resin microspheres first calculates the patient's actual BSA: the patient's height in meters raised to a power of 0.725 , multiplied by the patient's weight in kilograms raised to a power of 0.425 , multiplied by a constant $(0.20247)$. The activity of resin microspheres in gigabecquerels based on the BSA method equals the volume of the tumor divided by the sum of the tumor volume and the normal-liver volume, both calculated by cross-sectional imaging. This quotient is then added to the patient's BSA minus 0.2.

The assumption of a uniform dose distribution is another limiting factor in the current calculations because blood flow is preferentially diverted toward tumor compared with normal parenchyma (38). Attempts have been made to account for this nonuniform distribution of blood flow. One study incorporated a subjectively determined ratio of tumor hypervascularity relative to adjacent normal liver tissue and found more than a doubling of the median calculated dose delivered to tumor, from 521 to 1,214 Gy (39). These findings resulted in the development of a more realistic model known as the 3-compartment model, which adds the tumor-to-liver uptake ratio when calculating dose and has shown better dose estimates than those obtained with the empiric or BSA model $(40,41)$.

Although the BSA model is a commonly used method for ${ }^{90} \mathrm{Y}$ dosing because of its relative simplicity, the resulting dose does not correlate well with liver volume, particularly in the setting of very low or very high tumor burden $(37,41)$. This discrepancy can be further exacerbated if the patient has a history of liver surgery, a major consequence of which is overdosing, which can lead to increased deposition of dose in normal liver parenchyma and potentially fatal side effects. Another dosing model, MIRD, likely represents a more accurate measurement of ${ }^{90} \mathrm{Y}$ radioembolization activity (37,41-42). MIRD operates under the basis that any administered dose is going to affect 3 different compartments: tumor, normal liver parenchyma, and lung parenchyma $(37,42)$. The activity of the ${ }^{90} \mathrm{Y}$ particles is equivalent to the nominal dose to the liver, in grays, multiplied by the mass of the liver, in kilograms, divided by 50 . The dose administered to each of the 3 compartments can be calculated by multiplying the total activity of the ${ }^{90} \mathrm{Y}$ therapy by the fractional uptake of each compartment (liver, tumor, or lung), multiplying that number by 184,000 , and dividing that product by the mass of the given compartment (42).

The U.S. Nuclear Regulatory Commission, in consultation with the American College of Radiology, released guidelines on the qualifications required for a physician to administer ${ }^{90} \mathrm{Y}$ therapy $(43,44)$. There are 3 requirements to become an authorized user for ${ }^{90} \mathrm{Y}$ : completing at least 3 manufacturer-simulated cases, obtaining a license amendment declaring the operator to be an authorized user, and performing 3 in vivo cases with each type of ${ }^{90} \mathrm{Y}$ microsphere.

\section{PROCEDURE TECHNIQUE AND POSTPROCEDURAL CONCERNS}

As with any intraarterial therapy, the administering physician must decide whether to access the radial or the femoral artery before beginning ${ }^{90} \mathrm{Y}$ radioembolization. Although much of the traditional interventional radiology literature discusses performing procedures with femoral artery access, some hospitals have started performing this procedure with transradial access (45). Initially described in the interventional cardiology literature, radial access has gained prominence in interventional radiology as a safe alternative for embolization procedures within the abdominal viscera. Compared with femoral access, radial access carries less risk of bleeding complications and is easier in obese patients.

After arterial access is obtained via the Seldinger technique, the aorta, celiac artery, and hepatic artery branches are catheterized with either a 4 - or 5-French catheter system (9). A coaxial $0.8255-\mathrm{mm}(0.0325$-in) system is then advanced into the target artery, where the ${ }^{90} \mathrm{Y}$ microspheres are administered. It is important to avoid stasis or reflux of the ${ }^{90} \mathrm{Y}$ microspheres to prevent a potential lung shunt or nontarget injuries, particularly for resin microspheres. Depending on the extent of disease, differing levels of subselection may be chosen, including subbranches supplying the tumor, segmental branches, and lobar branches. Radiation segmentectomy is radioembolization of 2 or fewer hepatic segments based on the Couinaud classification system during a single session. This technique is typically used for tumors smaller than 5 $\mathrm{cm}$ that are not amenable to curative therapies such as surgical resection or percutaneous ablation (36). Radiation lobectomy consists of infusion of ${ }^{90} \mathrm{Y}$ particles into one of the lobar arteries, usually the right, to bring about hypertrophy of the contralateral lobe of the liver $(9,22)$. Once the contralateral lobe has hypertrophied to $20 \%-40 \%$ of the total liver volume, the embolized lobe can be resected $(9,22)$.

Once the artery has been selected, the dose can be administered (33). The dose itself is stored in a Nalgene plastic container (Thermo Fisher Scientific Inc.), which contains the dose and attached tubing to connect to the arterial catheter. The infusion technique differs between glass and resin microspheres. Flushing of the line for glass microspheres is imperative to ensure complete delivery of the dose within either a 4- or 5-French catheter system, at a rate of infusion identical to normal hepatic flow. For resin microspheres, the greater number of spheres needed may result in an embolic or stasis phenomenon within the arteries. Fluoroscopic guidance with contrast medium is imperative to ensure maximal vascular saturation. Radiation monitoring of the dose vial can also be performed to ensure that the optimal dose has been administered to the patient.

Within $24 \mathrm{~h}$ after injection of ${ }^{90} \mathrm{Y}$, a Bremsstrahlung SPECT/CT scan may be obtained to ensure that the ${ }^{90} \mathrm{Y}$ microspheres have 
been deposited in the appropriate liver territory (31). Concordance with post-99m Tc-MAA SPECT/CT scans should be seen, with absence of radioactivity within extrahepatic areas (Fig. 2). Axial SPECT/CT and planar scintigraphy images are usually obtained via a dual-head $\gamma$-camera (30).

Today, radioembolization of hepatic tumors with ${ }^{90} \mathrm{Y}$ microspheres can be performed on an outpatient basis, with patients staying in the hospital for only $2-6 \mathrm{~h}$ after the procedure for recovery (9). Posttreatment precautions may vary between treatment facilities, including precautions for the administering physicians. Patients may be prescribed proton pump inhibitors for gastrointestinal ulcer prophylaxis or steroid tapers to treat postradiation fatigue. Although ${ }^{90} \mathrm{Y}$ radiation exposure to other people is typically limited, patients should still be fully instructed about radiation safety precautions, as radioactivity can be detected in urine at trace levels.

\section{POSTPROCEDURAL IMAGING}

Initial follow-up scans should be performed 1-3 mo after therapy, with contrast-enhanced CT or MRI of the abdomen, although optimal changes are seen at 3-6 mo (9). Although tumor appearance differs between the 2 modalities, treatment response is characterized similarly (46). If treatment is successful, tumor size and contrast enhancement will decrease secondary to decreased tumor vascularity, consistent with tumor necrosis (Fig. 6). Diffusion restriction will be increased in MRI secondary to compromised cell-membrane integrity due to necrotic tissues. There may be a paradoxic increase in tumor size after ${ }^{90} \mathrm{Y}$ radioembolization has produced an appropriate treatment response; however, any size increase is usually secondary to cell death of the surrounding normal liver parenchyma, which is incorrectly interpreted as tumor growth. An additional pitfall in posttreatment imaging is ring enhancement around the necrotic cavity; this finding is occasionally misinterpreted as residual tumor but actually represents fibrosis. If follow-up PET scans are performed, tumors show a decrease in size and metabolic activity. Postprocedural imaging also provides for evaluation of potential complications from ${ }^{90} \mathrm{Y}$ radioembolization.

\section{POTENTIAL SIDE EFFECTS}

Although ${ }^{90} \mathrm{Y}$ radioembolization is typically well tolerated, there are multiple potential complications, with a low incidence overall (33). Some of these complications are germane to other minimally invasive treatments of liver malignancy (46). Perihepatic

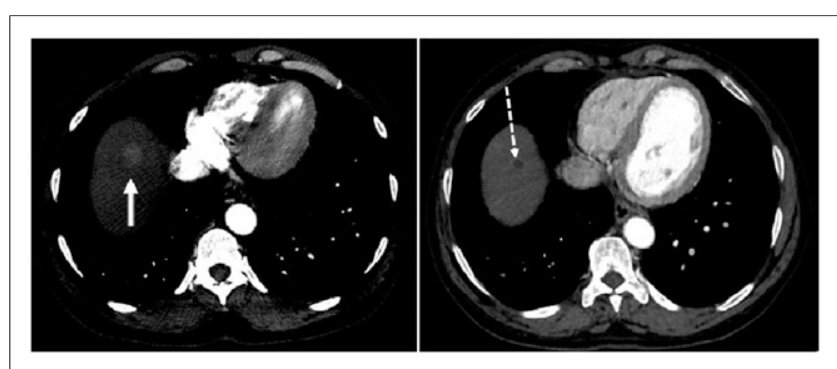

FIGURE 6. Axial arterial-phase CT images from 68-y-old man before (left) and 1 mo after (right) ${ }^{90} \mathrm{Y}$ therapy. Tumor (solid arrow) enhances before treatment, consistent with hepatocellular carcinoma, but after treatment shows no evidence of enhancement within treatment cavity (dashed arrow). fluid and hepatic abscesses can be found in any therapy that causes tumor necrosis (33). Contrast-induced nephrotoxicity or an allergic reaction to iodinated contrast medium can occur with any angiographic procedure. Arterial injury can also occur during transarterial therapy, including bleeding, dissection, or pseudoaneurysm.

The most common side effect from ${ }^{90} \mathrm{Y}$ therapy is postradioembolization syndrome, characterized by fatigue, nausea, vomiting, or abdominal pain (33). These symptoms may be treated as needed with over-the-counter analgesics for pain and antiemetics for nausea and vomiting.

Although many steps are taken during dosing to ensure that nontumor liver parenchyma is minimally affected, variability in dosing due to a specific patient's physiology can result in parenchymal complications (33). The most serious of these is radioembolization-induced liver disease: severe liver toxicity and dysfunction secondary to radiation. Multiple treatments and additional external-beam radiation increase the risk of this disease. Additional effects to the liver parenchyma include hepatic fibrosis and portal hypertension.

Because of its relationship with the liver, the biliary system is a potential site of complications from ${ }^{90} \mathrm{Y}$ radiotherapy (33). Cholangiohepatitis and bile duct necrosis have occurred after ${ }^{90} \mathrm{Y}$ therapy and may be associated with liver capsule retraction (46). Radiation cholecystitis results from nontarget embolization of the cystic artery; this complication can be prevented with prophylactic embolization and injection distal to its origin from the hepatic arteries $(31,33)$. Radiation cholecystitis is treated in the same way as any other cholecystitis: with cholecystectomy (33).

Gastric and duodenal ulceration secondary to nontarget embolization has been described in the literature and can be prevented with prophylactic embolization of the gastroduodenal artery, gastric arteries, or any collateral vessels noted during preplanning arteriography $(30,33)$. Self-limited radiation dermatitis may occur because of shunting of the ${ }^{90} \mathrm{Y}$ microspheres to the abdominal wall via the hepatic falciform artery $(30,33)$. Additional sites of nontarget embolization include the pancreas (radiation-induced pancreatitis) and the lungs (radiation pneumonitis) (33).

\section{CONCLUSION}

Radioembolization with ${ }^{90} \mathrm{Y}$ is an efficacious treatment for both primary and metastatic malignancies of the liver. For patients in whom surgery or other locoregional therapies may be contraindicated, ${ }^{90} \mathrm{Y}$ microsphere therapy provides an opportunity for improved survival and decreased disease burden. Understanding how the treatment is performed, the expected imaging findings after treatment, and potential complications is paramount for every diagnostic radiologist, interventional radiologist, and nuclear medicine physician to accurately serve this growing patient population.

\section{REFERENCES}

1. Ariel IM. Treatment of inoperable primary pancreatic and liver cancer by the intra-arterial administration of radioactive isotopes ( $\mathrm{Y}$ radiating microspheres). Ann Surg. 1965;162:267-278.

2. Raval M, Bande D, Pillai AK, et al. Yttrium- 90 radioembolization of hepatic metastases from colorectal cancer. Front Oncol. 2014;4:120.

3. Kim YC, Kim YH, Uhm SH, et al. Radiation safety issues in Y-90 microsphere selective hepatic radioembolization therapy: possible radiation exposure from the patients. Nucl Med Mol Imaging. 2010;44:252-260.

4. Carr BI. Hepatic arterial ${ }^{90}$ Yttrium glass microspheres (TheraSphere) for unresectable hepatocellular carcinoma: interim safety and survival data on 65 patients. Liver Transpl. 2004;10(suppl 1):S107-S110. 
5. Biederman DM, Titano JJ, Tabori NE, et al. Outcomes of radioembolization in the treatment of hepatocellular carcinoma with portal vein invasion: resin versus glass microspheres. J Vasc Interv Radiol. 2016;27:812-821.

6. Dancey JE, Shepherd FA, Paul K, et al. Treatment of nonresectable hepatocellular carcinoma with intrahepatic ${ }^{90}$ Y-microspheres. J Nucl Med. 2000;41:16731681.

7. Ibrahim SM, Lewandowski RJ, Sato KT, et al. Radioembolization for the treatment of unresectable hepatocellular carcinoma: a clinical review. World J Gastroenterol. 2008;14:1664-1669.

8. Johnson PJ. Non-surgical treatment of hepatocellular carcinoma. HPB (Oxford). 2005;7:50-55.

9. Pasciak AS, Bradley Y, McKinney JM. Handbook of Radioembolization, Physics, Biology, Nuclear Medicine, and Imaging. Boca Raton, FL; CRC Press; 2016.

10. Biederman DM, Titano JJ, Korff RA, et al. Radiation segmentectomy versus selective chemoembolization in the treatment of early-stage hepatocellular carcinoma. J Vasc Interv Radiol. 2018;29:30-37.

11. Biederman DM, Titano JJ, Bishay VL, et al. Radiation segmentectomy versus TACE combined with microwave ablation for unresectable solitary hepatocellular carcinoma up to $3 \mathrm{~cm}$ : a propensity score matching study. Radiology. 2017;283: 895-905.

12. Swinburne NC, Biederman DM, Besa C, et al. Radioembolization for unresectable intrahepatic cholangiocarcinoma: review of safety, response evaluation criteria in solid tumors 1.1 imaging response and survival. Cancer Biother Radiopharm. 2017;32:161-168.

13. Mouli S, Memon K, Baker T, et al. Yttrium-90 radioembolization for intrahepatic cholangiocarcinoma: safety, response, and survival analysis. J Vasc Interv Radiol. 2013;24:1227-1234.

14. Hickey R, Lewandowski RJ, Prudhomme T, et al. ${ }^{90} \mathrm{Y}$ radioembolization of colorectal hepatic metastases using glass microspheres: safety and survival outcomes from a 531-patient multicenter study. J Nucl Med. 2016;57:665-671.

15. Van Hazel G, Blackwell A, Anderson J, et al. Randomised phase 2 trial of SIRSpheres plus fluorouracil/leucovorin chemotherapy versus fluorouracil/leucovorin chemotherapy alone in advanced colorectal cancer. J Surg Oncol. 2004;88: 78-85.

16. Van Hazel GA, Heinemann V, Sharma NK, et al. SIRFLOX: randomized phase III trial comparing first-line mFOLFOX6 (plus or minus bevacizumab) versus mFOLFOX6 (plus or minus bevacizumab) plus selective internal radiation therapy in patients with metastatic colorectal cancer. J Clin Oncol. 2016;34:17231731 .

17. Kennedy A. Radioembolization of hepatic tumors. J Gastrointest Oncol. 2014;5: 178-189.

18. Kennedy AS, Coldwell D, Nutting C, et al. Resin ${ }^{90}$ Y-microsphere brachytherapy for unresectable colorectal liver metastases: modern USA experience. Int J Radiat Oncol Biol Phys. 2006;65:412-425.

19. Gibbs P, Gebski V, Van Buskirk M, et al. Selective internal radiation therapy (SIRT) with yttrium-90 resin microspheres plus standard systemic chemotherapy regimen of FOLFOX versus FOLFOX alone as first-line treatment of non-resectable liver metastases from colorectal cancer: the SIRFLOX study. BMC Cancer. 2014; $14: 897$.

20. Kennedy AS, Dezarn WA, McNeillie P, et al. Radioembolization for unresectable neuroendocrine hepatic metastases using resin ${ }^{90} \mathrm{Y}$-microspheres: early results in 148 patients. Am J Clin Oncol. 2008;31:271-279.

21. FDA news release: FDA approves new treatment for certain digestive tract cancers. U.S. Food and Drug Administration website. www.fda.gov/NewsEvents/ Newsroom/PressAnnouncements/ucm594043.htm. Published January 28, 2018.

22. Braat AJ, Huijbregts JE, Molenaar IQ, Borel Rinkes IH, Van den Bosch MA, Lam MG. Hepatic radioembolization as a bridge to liver surgery. Front Oncol. 2014;4:199.

23. Gaba RC. Planning arteriography for yttrium- 90 microsphere radioembolization. Semin Intervent Radiol. 2015;32:428-438.

24. Carretero C, Munoz-Navas M, Betes M, et al. Gastroduodenal injury after radioembolization of hepatic tumors. Am J Gastroenterol. 2007;102:1216-1220.

25. Floridi C, Radaelli A, Abi-Jaoudeh N, et al. C-arm cone-beam computed tomography in interventional oncology: technical aspects and clinical applications. Radiol Med (Torino). 2014;119:521-532.
26. Refaat R, Hasan MS. The relationship between the percentage of lung shunting on Tc-99m macroaggregated albumin (Tc-99m MAA) scan and the grade of hepatocellular carcinoma vascularity. Egyptian J Radiol Nucl Med. 2014;45:2.

27. Ho S, Lau WY, Leung WT, et al. Arteriovenous shunts in patients with hepatic tumors. J Nucl Med. 1997;38:1201-1205.

28. Gulec SA, Mesoloras G, Dezarn WA, McNeillie P, Kennedy AS. Safety and efficacy of Y-90 microsphere treatment in patients with primary and metastatic liver cancer: the tumor selectivity of the treatment as a function of tumor to liver flow ratio. J Transl Med. 2007;5:15.

29. Knesaurek K, Machac J, Muzinic M, Dacosta M, Zhang Z, Heiba S. Quantitative comparison of yttrium-90 $\left({ }^{90} \mathrm{Y}\right)$-microspheres and technetium-99m $\left({ }^{99 \mathrm{~m}} \mathrm{Tc}\right)$ macroaggregated albumin SPECT images for planning ${ }^{90} \mathrm{Y}$ therapy of liver cancer. Technol Cancer Res Treat. 2010;9:253-262.

30. Murthy R, Nunez R, Szklaruk J, et al. Yttrium-90 microsphere therapy for hepatic malignancy: devices, indications, technical considerations, and potential complications. Radiographics. 2005;25(suppl 1):S41-S55.

31. Ahmadzadehfar H, Duan H, Haug AR, Walrand S, Hoffmann M. The role of SPECT/CT in radioembolization of liver tumours. Eur J Nucl Med Mol Imaging. 2014;41(suppl 1):S115-S124.

32. Abdelmaksoud MH, Hwang GL, Louie JD, et al. Development of new hepaticoenteric collateral pathways after hepatic arterial skeletonization in preparation for yttrium-90 radioembolization. J Vasc Interv Radiol. 2010;21:1385-1395.

33. Salem R, Thurston KG. Radioembolization with ${ }^{90}$ Yttrium microspheres: a stateof-the-art brachytherapy treatment for primary and secondary liver malignancies. Part 1: Technical and methodologic considerations. J Vasc Interv Radiol. 2006;17: 1251-1278.

34. Riaz A, Awais R, Salem R. Side effects of yttrium- 90 radioembolization. Front Oncol. 2014;4:198.

35. Vouche M, Lewandowski RJ, Atassi R, et al. Radiation lobectomy: time-dependent analysis of future liver remnant volume in unresectable liver cancer as a bridge to resection. J Hepatol. 2013;59:1029-1036.

36. Vouche M, Habib A, Ward TJ, et al. Unresectable solitary hepatocellular carcinoma not amenable to radiofrequency ablation: multicenter radiology-pathology correlation and survival of radiation segmentectomy. Hepatology. 2014;60:192-201.

37. Mosconi C, Cappelli A, Pettinato C, Golfieri R. Radioembolization with yttrium90 microspheres in hepatocellular carcinoma: role and perspectives. World $J$ Hepatol. 2015;7:738-752.

38. Lau WY, Leung TW, Ho S, et al. Diagnostic pharmaco-scintigraphy with hepatic intra-arterial technetium-99m macroaggregated albumin in the determination of tumour to non-tumour uptake ratio in hepatocellular carcinoma. $\mathrm{Br} J$ Radiol. 1994;67:136-139.

39. Riaz A, Gates VL, Atassi B, et al. Radiation segmentectomy: a novel approach to increase safety and efficacy of radioembolization. Int J Radiat Oncol Biol Phys. 2011;79:163-171.

40. Kappadath SC, Erwin W, Mutha P, Prasad S, Murthy R. Comparison of three radiation dosimetry models for yttrium- 90 microsphere radioembolotherapy [abstract]. J Nucl Med. 2009;50(suppl 2):209.

41. Samim M, Van Veenendaal LM, Braat M, et al. Recommendations for radioembolisation after liver surgery using yttrium-90 resin microspheres based on a survey of an international expert panel. Eur Radiol. 2017;27:4923-4930.

42. Gulec SA, Mesoloras G, Stabin M. Dosimetric techniques in ${ }^{90} \mathrm{Y}$-microsphere therapy of liver cancer: the MIRD equations for dose calculations. J Nucl Med. 2006;47:1209-1211.

43. Brink J. Re: (docket ID NRC-2017-0215) yttrium-90 microsphere brachytherapy sources and devices TheraSphere ${ }^{\circledR}$ and SIR-Spheres ${ }^{\circledR}$; comments of the American College of Radiology. American College of Radiology website. https:// www.acr.org/-/media/ACR/Files/Advocacy/Regulatory-Issues/NRC-Draft-Guidance-Y-90-Microsphere-Brachytherapy.pdf?la=en. Published February 7, 2018.

44. Yttrium-90 microsphere brachytherapy sources and devices: TheraSphere ${ }^{\circledR}$ and SIRSpheres ${ }^{\circledR}$-licencing guidance. Nuclear Regulatory Commission website. https:// www.nrc.gov/docs/ML1535/ML15350A099.pdf. Published February 12, 2016.

45. Bishay VL, Biederman DM, Ward TJ, et al. Transradial approach for hepatic radioembolization: initial results and technique. AJR. 2016;207:1112-1121.

46. Atassi B, Bangash AK, Bahrani A, et al. Multimodality imaging following ${ }^{90} \mathrm{Y}$ radioembolization: a comprehensive review and pictorial essay. Radiographics. 2008;28:81-99. 